\title{
Guiding principles for creating environmental regulations that work
}

\author{
T. S. Mullikin \\ Government, Policy and Regulatory Affairs, \\ Moore \& Van Allen PLLC, USA
}

\begin{abstract}
Creating sensible policies and regulations that reduce, stop and ultimately reverse the upward trend in greenhouse gas emissions are the topics of heated debate worldwide. By applying five guiding principles based upon years of experience formulating policies and regulations in a legal/legislative setting, workable environmental regulations can be developed and implemented.

Five guiding principles require that policies and regulations be: 1) flexible in application 2) global in scope 3) market-driven in implementation 4) firmly anchored in economic reality 5) successful in demonstrating tangible environmental benefits.
\end{abstract}

Keywords: government policies, regulations, climate change, environmental legislation, workable solutions, greenhouse.

\section{Regulations must be flexible in application}

Scientists do not deal in truths and untruths so much as they explore truths and "new" truths arising from additional research data. The constantly evolving knowledge from scientific methods and measurements requires that lawmakers and regulators be flexible when attempting to regulate man-made activities that result in a significant effect upon the Earth's environment.

As early as 1896, Nobel prize-winning chemist Svante Arrhenius of Sweden helped demonstrate how difficult it is to predict the effects of humankind's activities on our environment. Based upon his calculations, Arrhenius predicted that doubling the amount of carbon dioxide covering the Earth would result in a 5-6 degree Centigrade increase in the Earth's surface temperature [1]. But he also thought it would take 3,000 years to occur. 
In reality, it has taken only 100 years for levels to increase by 30 percent. Fortunately, scientists can gauge with increased accuracy the temperature effects of greenhouse gases. Instead of the temperature rising 5-6 degrees as earlier predicted, scientists now estimate temperature increases at about half that, 2-3 degrees Centigrade [1].

While information is continuously changing and evolving, one constant that remains is that policies and regulations must be able to take into account new science and scientific data and be prepared to speed up or slow down regulatory induced controls as necessary.

For example, research in the Gubantonggut Desert in China indicates that deserts may take up carbon dioxide at the same rate as some temperate forests. Research in the American Mojave Desert resulted in similar findings.

Scientists need to do much research yet in this area, but if the initial findings hold true, then deserts and semi-arid regions of the world may be absorbing 5.2 billion tons of carbon a year. That amount is roughly half the amount of carbon released annually from the burning of all fossil fuels [2].

It is imperative, then, that enacted rules, regulations and policies be adaptable to changing conditions and new scientific findings.

\section{Regulations must be global in scope}

Early environmental legislation in the United States - such as Clean Air and Clean Water Acts - frequently addressed pollution from a local, state or even regional level. Nevertheless, in the 1970s and 1980s, another pollution problem called "acid rain" began receiving great attention. Forests in high mountain areas - particularly in the Eastern U.S., such as the Catskills, Adirondacks and Blue Ridge - were showing signs of damage and decay.

In Germany, trees damaged by acid rain appeared in nearby Eastern bloc countries. Scientists and politicians suddenly became aware that pollution knows no state or national boundaries.

Finally, the defining event that made the world aware of the global nature of the earth's physical environment occurred April 28, 1986, when technicians at Sweden's Forsmark Nuclear Power Plant outside Stockholm detected radiation levels inside the plant that were four to five times normal readings.

The mysterious radiation was not coming from Swedish reactors on site. Eventually, investigators concluded that prevailing winds were carrying dangerous radiation from the former Union of Soviet Socialist Republics (USSR).

Over the next several days, the world gradually learned that an explosion and fire at the Chernobyl nuclear power plant in northern Ukraine was spewing tons of dangerous radioactive isotopes into the atmosphere every day the fire raged out of control.

Even though Stockholm is 1,000 miles from Chernobyl, it received a significant amount of radioactivity from the accident. Chernobyl opened the world's eyes to the fact that environmental events in one country affect nearly 
every other country throughout the world. Thus, to be effective, we must implement pollution control measures on a worldwide basis.

Historically, nations have successfully banded together globally to solve environmental problems. One such example involves a family of chemicals known as chlorofluorocarbons - or CFCs for short. While these chemicals have been around since the 1930s, they did not achieve widespread use until the 1950s and $60 \mathrm{~s}$ when they served as refrigerants in air conditioning compressors and as an inert propellant in aerosol sprays.

By the 1970s, research satellites already were beginning to pick up signs that the earth's ozone level was starting to diminish. Slowly the issue took on an international urgency. Various nations agreed to ban CFCs in aerosols but industry fought banning valuable CFCs in other applications.

In the early 1980s, models of the atmospheric chemistry involving CFCs became more and more complex, and various challenges arose to the validity of the science. Apparently, the industrial nations of the world required a great shock before they could commit to the uncomfortable task of phasing out CFCs.

That shock came in a 1985 field study by J. C. Farman, B. G. Gardiner and J. D. Shanklin of the British Antarctic Survey. Their study, published in Nature, May 1985, summarized data showing that ozone levels had dropped to $10 \%$ below normal January levels for Antarctica. A hole was developing in the ozone layer over the South Pole [3].

Just as importantly as the discovery of the hole in the ozone, these scientists demonstrated in a startling way that chemicals released by industrialized nations in major population centers of Europe and North America could gather over the poles and collectively change the atmosphere on a global scale.

September 2007 marked the 20th anniversary of the Montreal Protocol on Substances that Deplete the Ozone Layer. Initially, 55 countries and the European Economic Commission negotiated this historic international agreement. These countries banded together in the mid-1980s to set a schedule for freezing and then phasing out the production of CFCs. Eventually 191 countries joined the agreement including the United States under President Ronald Reagan. The United States ended CFC production 12 years ago.

Due to its widespread adoption and implementation, the Montreal Protocol has been regarded as an example of exceptional international co-operation by world leaders, including Kofi Annan, United Nations Nobel Peace Prize-winning Secretary General from 1997 to 2006 . He said that the agreement is "Perhaps the single most successful international agreement to date...." And scientific evidence shows that CFCs in the lower troposphere are decreasing, a change that must occur before the ozone layer can regenerate in the upper levels of the stratosphere.

The significance of the ozone protection initiative is that action took place on a global scale even though there were challenges to the science involved. While eliminating greenhouse gases presents much tougher challenges than replacing ozone-depleting substances, the experience illustrates that nations can come together to achieve positive results even when there is disagreement about the science or politics involved. As illustrated in the ozone situation, remedies must 
be approached on a global basis or emissions will continue to emanate from other countries.

Just as electricity seeks the path of least resistance, industry locates where conditions are more favorable to economic success. If climate change issues are not addressed globally, then the emissions will migrate from advanced industrialized nations to other areas of the world where environmental controls are less restrictive.

For example, if U.S. climate change regulations place a burdensome tax or fee on carbon emissions, a business may be forced to relocate to a country where these regulations do not exist or are only minimally enforced. Which means that the U.S. may decrease its total carbon emissions when the polluting business moves overseas. The problem does not go away. It has just moved to another part of the world where there is less chance the problem will be mitigated.

\section{Regulations must be market driven}

Another lesson learned from the ozone experience is this: one of the key factors to change is motivating industry - especially large corporations - to develop the technologies that make change happen. Nothing drives change like economic success. One of the most notable achievements of the Montreal protocol was that the chemical companies quickly recognized the market opportunities created by the agreement.

With the discovery of a hole in the ozone, political forces began pushing for regulation of ozone-depleting chemicals. Chemical giant DuPont, which produced more than half the $\mathrm{CFCs}$, then assumed a leadership role, immediately stepping up efforts to develop ozone-safe substitutes for CFCs.

The firm spent $\$ 500$ million to develop substitutes and build production facilities. Within a few years they were supplying refrigeration and airconditioning manufactures with profitable CFC substitutes [4].

DuPont created a new model for corporate behavior by teaming up with environmentalists to ban CFCs. DuPont correctly recognized the new markets that needed CFC replacements and leveraged their research and development strengths to fill diverse market niches.

The phase out of CFCs was assisted by the simple and unambiguous timeframe set out in the Montreal Protocol for the end to CFC production. By setting reasonable schedules, companies were able to rationally predict and develop markets for alternatives.

The CFC phase out teaches lessons today about the challenges created by greenhouse gas emissions. The speed with which CFC substitutes were rushed to market was based upon prospects of a lucrative new market for companies such as DuPont. Therefore, the effectiveness of any strategy on global climate change will depend upon how well it creates new markets.

It is estimated that the market for low-carbon energy products will reach $\$ 500$ billion by 2050 , according to the Stern Review on the Economics of Climate Change, released last year by the British Treasury. The report states that the 
transition to a low-carbon economy will bring challenges for competitiveness, but also opportunities for growth [5].

Market-driven incentives to reduce emissions work best. All regulations that affect individuals and industry must be crafted carefully to avoid creating burdensome requirements. The most effective policies will encourage the marketplace by offering tax rebates, development funds and other economic incentives to jump start technology and implementation into commercial production. For example, consumers could be offered tax credits to purchase alternative fuel vehicles or to replace inefficient home heating systems with solar-powered systems. Once the consumer demand has been established, then the private sector should enthusiastically manufacture the products required and assist in building the infrastructure. If hydrogen fuel vehicles become popular, then energy companies will have the incentive to create the fuel and distribution centers where motorists can conveniently refuel. Free enterprise is a powerful force when the driving factors are economic.

State governments in the United States are also taking steps to increase the amount of energy consumed from renewable resources. North Carolina, for example, the state in which our firm operates, has authorized tax credits for solar power generation. Legislation also requires that the state generate at least 12.5 percent of its power from renewable resources by 2021. This step establishes North Carolina as the first state in the Southeastern U.S. to adopt renewable energy standards.

The state has enacted additional legislation providing tax credits to both residential and corporate customers in North Carolina. The credit covers up to $35 \%$ of the cost of a solar electricity or other renewable energy system, capped at $\$ 10,500$ for residential systems and a hefty $\$ 2.5$ million for commercial and industrial systems.

Federal tax credits provide homeowners 30 percent of the cost of a project up to a maximum credit of $\$ 1,500$ on a broad range of home energy improvements, such as energy saving doors, windows, insulation, roofing, energy efficient heating, air conditioning and ventilation systems and water heaters.

These state and federal tax rebates provide attractive incentives for homeowners to voluntarily make significant long-term infrastructure improvements to their dwelling

On the other hand, legislated regulatory systems to reduce emissions - such as cap and trade - are tricky and can result in an increase in government spending and a decrease in revenues, according to an April 2007 report by the U.S. Congressional Budget Office report. Such changes would come about due to rising energy costs for government, which would also be affected by the price of energy and other carbon-intensive goods and services. Businesses that are negatively affected by carbon costs create less revenue, which means less tax money will be paid to government.

If the cap-and-trade system is implemented, it may bring about economic changes too quickly and lead to an economic slowdown. Once again, government suffers because of falling tax revenues from tax-paying businesses and corporations [6]. 


\section{Regulations must be anchored in economic reality}

The world economy has an environment of its own, just as sensitive to change as our physical environment. For almost every action in the world, there is a measurable economic reaction. Therefore, any policy changes and regulations by a sovereign government also result in economic impacts. The key is in moving forward, making the world a better place to live without stopping economic growth. Economic realities cannot be ignored.

One of the most urgent questions that must be answered in reducing greenhouse emissions is, "Who will pay the bill?" Will costs be handled on an individual level, by passing costs on to consumers who create the demand for energy and other carbon-producing products? Carbon taxes on working households living from paycheck to paycheck may be saddled with the burden of extra costs. On the other hand, direct costs can create dramatic changes in behavior.

Individuals and families may have a significant economic incentive to reduce carbon consumption if charged for it. Likewise, through higher taxes coupled with manufacturer rebates and government tax incentives, a family may find it much more cost efficient to trade in an old gas-guzzler automobile for a new rechargeable electric, a gas hybrid or a fuel cell-powered car.

On the other hand, a large producer of carbon, such as a coal-fired electric power plant, may be in a better position to capture and sequester emissions on a commercial scale and share the costs with consumers in the form of higher electric rates. Here again, the consumer would have an incentive to reduce electric consumption to save money. Economics would drive conservation.

Cap-and-trade systems have the added drawback of significant administrative costs. To reduce emissions through a formal system of incremental reductions requires measures, databases and personnel and systems for operation. In other words, an expansion of government. While carbon credit auctions generate government revenue, money for investing in renewable energy projects or alternative fuels can be significantly reduced due to excessive administrative costs, a constant concern for local government.

And what other effects would carbon controls create? If a consumer has less money to spend, will it damper economic growth? If consumers stop buying, will that reduce jobs, further slowing down the economy? Will the economic stagnation affect large industrialized nations the most or will emerging industrial nations of Asia and South America be affected equally?

Past experience in the U.S. in dealing with environmental challenges involved reducing sulfur emissions, which combined with rain to produce an "acid rain." The threat from acid rain covered many areas of the economy, such as damage to public property and landscapes, harmful effects on wildlife in streams and ponds and deforestation. Sulfur dioxide emissions also endangered human lungs, particularly Americans who were already suffering chronic lung disease. 


\section{Regulations must result in real environmental benefits}

One of the most significant lessons that can be learned from the efforts to eradicate CFCs is that policies and regulations to accomplish environmental changes must actually do what they are intended to do. For example, scientists as well as policy makers recognized that the only way to protect the ozone layer was to eliminate CFCs.

Simply reducing the amount would not end the environmental threat. Neither would a cap-and-trade system that has been used successfully in other environmental applications, such as sulfur dioxide emissions.

It is also important to separate similar objectives, such as increasing energy independence and reducing greenhouse gas emissions. These separate objectives are obviously not the same. So policy changes and economic incentives should be aimed at reducing carbon through clean fuels - such as hydrogen, nuclear, solar and wind-generated electricity - and other energy sources that do not produce carbon as a waste product.

On the other hand, making a country energy self-sufficient may involve intense use of ethanol, natural gas or other combustible fuels that equally produce greenhouse gas emissions.

Ultimately, the cleanest, most efficient electric generation plant is the one that did not have to be built. Increased energy efficiency and improved technology are the quickest ways to effect this type of greenhouse gas reductions. Some industries have already taken these steps. The American steel industry is a prime example.

According to the International Iron and Steel Institute, American steelmakers have greatly increased steel production while proportionately reducing carbon dioxide emissions. In 1990, American manufacturers produced 88.7 million metric tons of steel and 85 million metric tons of carbon dioxide as a by-product. In 2005, steel producers turned out 93.9 million metric tons of steel and reduced carbon dioxide emissions to 45.2 million metric tons. That reduction exceeds the 1997 Kyoto Protocol target by 900 per cent.

In addition to the use of more energy efficient electric arc furnaces, other manufacturing technology breakthroughs, such as the transition from ingot casting of steel to continuous casting and strip casting, have reduced energy requirements.

The changing economics of the iron and steel industry essentially drove progress in energy efficiency. A by-product of that change has been a dramatic reduction in greenhouse gas emissions. The recent increase in energy prices has the potential to spur the same kind of reductions in other sectors of the economy, arguably far faster and more cost effectively than through a government implemented environmental program.

One of government's most important roles is to identify proposed environmental policy objectives. Are they to reduce use of fossil fuels or to encourage energy efficiency and conservation? Is the objective to improve the quality of air or to spur consumers to use an alternative fuel? 
Another way in which government can help is by ensuring that if a marketbased approach is adopted, it is working. Government intervention has the power to provide incentives that remove barriers to environmentally positive behaviors.

For example, government tax policy can provide incentives that encourage gasoline service stations to augment their traditional petroleum fuel offerings with hydrogen fueling facilities. When hydrogen fuel is easier to obtain, motorists will be more inclined to buy and use hydrogen-powered vehicles.

\section{Summary}

Effective regulations must take into account the needs of all stakeholders on a global basis. Global environmental issues need global environmental solutions. Real leadership requires a more complex investigation into issues and solutions affecting global climate change issues.

Policies should be carefully aimed at achieving a particular objective without creating a burdensome regulatory environment. Private enterprise and market forces provide the greatest impetus for sustainable changes.

Most people have the potential to understand any issue once it is expressed in terms of dollars and cents. Policies that work leverage this principle by couching behavioral change - and acceptance of new energy sources and technology-in practical, economic terms.

\section{References}

[1] Sample, I. "The Father of Climate Change," The [Manchester] Guardian, June 30, 2005, http://www.guardian.co.uk/environment/2005/jun/30 /climatechange.climatechangeenvironment, accessed September 30, 2008.

[2] Stone, R. "ECOSYSTEMS: Have Desert Researchers Discovered a Hidden Loop in the Carbon Cycle?" Science June 13, 2008: Vol. 320. no. 5882, pp. 1409 - 1410, DOI: 10.1126/science.320.5882.1409, accessed December 3, 2008.

[3] Farman, J. C., B. G. Gardiner, and J. D. Shanklin. 1985. Large losses of total ozone in Antarctica reveal seasonal ClOx/NOx interaction. Nature 315: 20710.

[4] Rotman, D. "Remembering the Montreal Protocol," Technology Review, published by MIT, January 1, 2007, <http://www.technologyreview.com /energy/17994/page2/>, accessed October 3, 2008.

[5] STERN REVIEW: The Economics of Climate Change, Publication of HM Treasury, Office of Climate Change, <http://62.164.176.164/d/ Executive_Summary.pdf $>$ accessed October 10, 2008.

[6] "Trade-Offs in Allocating Allowances for CO2 Emissions." Report by U.S. Congressional Budget Office, April 25, 2007. 